\title{
META-ANALISIS PENGARUH STRATEGI PQ4R DALAM PEMBELAJARAN BAHASA INDONESIA DI SEKOLAH DASAR
}

\author{
Mohammad Heru Dwi Kurniawan ${ }^{{ }^{*},}$ Endang Sri Mujiwati ${ }^{2}$, Ita Kurnia ${ }^{3}$ \\ ${ }^{1,2,3}$ Program Studi PGSD Universitas Nusantara PGRI Kediri \\ Jl. K.H. Achmad Dahlan No. 76 Mojoroto Kota Kediri \\ *Corresponding Author: heru.dkurniawan31@gmail.com \\ Info Artikel \\ Sejarah Artikel: \\ Diterima: 07/08/2020 \\ Direvisi: $13 / 08 / 2020$ \\ Disetujui: $15 / 08 / 2020$ \\ Keywords: $\quad P Q 4 R$ \\ strategy, meta- \\ analysis, Effect size. \\ Indonesian Language

\section{Abstract} \\ This research aimed to analyze the effect of the PQ4R strategy on Indonesian Language \\ material. The PQ4R strategy was a learning strategy used that make students remember what \\ they read and what they can help in teaching and learning process in the class which was \\ conducted by reading the books. The research used a meta-analysis method by using two \\ national journal articles. The calculations on the two articles provided different results. The \\ results of the first analysis article had an effect size of (1.33) which means that it had the \\ highest effect size. While, in the second article it had the effect size of (0.84) which means \\ the effect size is high. The PQ4R strategy affected in learning outcomes and it can be used in \\ Indonesian in the high of the elementary school.
}

\begin{abstract}
Abstrak
Penelitian ini bertujuan untuk menganalisis pengaruh strategi $P Q 4 R$ pada materi bahasa Indonesia. Strategi $P Q 4 R$ merupakan strategi pembelajaran yang digunakan untuk membuat siswa mengingat apa yang mereka baca dan dapat membantu proses belajar mengajar di kelas yang dilaksanakan dengan kegiatan membaca buku. Metode yang digunakan dalam penelitian ini yaitu metode meta-analisis dengan menggunakan dua artikel jurnal nasional. Perhitungan pada dua artikel memberikan hasil yang berbeda. Pada analisis artikel yang pertama memiliki hasil effect size sebesar $(1,33)$ yang memilki arti effect size efek yang sangat tinggi. Artikel kedua besaranya efek sebesar (0.84) yang memiliki arti effect size tinggi. Strategi $P Q 4 R$ berpengaruh terhadap hasil belajar dan dapat digunakan dalam pembelajaran Bahasa Indonesia pada kelas tinggi Sekolah Dasar.
\end{abstract}

\section{"Alamat korespondensi:}

Program Studi PGSD

Fakultas Keguruan dan Ilmu Pendidikan

Universitas Nusantara PGRI Kediri,

Jalan K.H. Achmad Dahlan Mojoroto No. 76 Kota Kediri

E-mail heru.dkurniawan31@gmail.com
(C) 2020 Program Studi PGSD Universitas Flores

Email: primagistrauniflor@ gmail.com 


\section{PENDAHULUAN}

Bahasa Indonesia merupakan bahasa nasional dan bahasa negara. Sejak diikrarkan Sumpah Pemuda dalam kongres pemuda, bahasa Indonesia menjadi bahasa nasional. Selain itu, bahasa Indonesia sebagai bahasa negara ditetapkan dan dituangkan dalam pasal 36 Undang-Undang Dasar 1945.

Menurut Sugono (2009:3) "Bahasa Indonesia sebagai bahasa nasional berfungsi sebagai 1. Lambang kebanggaan nasional, 2. Lambang identitas nasional, 3. Alat pemersatu berbagai masyarakat yang berbeda-beda latar belakang sosial buadaya dan bahasanya, serta 4. Alat perhubungan antar budaya dan antar daerah". Sedangkan sebagai bahasa negara, bahasa Indonesia berfungsi sebagai 1. Bahasa resmi kenegaraan, 2. Bahasa pengantar resmi di lembaga-lembaga pendidikan, 3. Bahasa resmi didalam perhubungan pada tingkat nasional untuk kepentingan perencanaan dan pelaksanaan pembangunan serta pemerintahan, dan 4. Bahasa resmi dalam pengemban kebudayaan dan pemanfaatan ilmu pengetahuan serta teknologi modern. Bahasa Indonesia telah menjadi bahasa nasional bangsa Indonesia dan bahasa resmi Negara Kesatuan Repiblik Indonesia.

Menurut Samsiyah (2016:4) tujuan pembelajaran bahasa Indonesia di sekolah dasar antara lain agar peserta didik memiliki kemampuan sebagai berikut.

1. Berkomunikasi secara efektif dan efesien sesuai dengan etika yang berlaku baik secara lisan maupun tulis.

2. Menghargai dan bangga menggunakan bahasa Indonesia sebagai persatuan dan bahasa negara.

3. Memahami bahasa Indonesia dan menggunakan dengan tepat dan kreatif untuk berbagai tujuan.

4. Menggunakan bahasa Indonesia untuk meningkatkan kemampuan intelektual, serta kematangan emosional dan sosial.

5. Menikmati dan memanfaatkan karya sastra untuk memperluas wawasan, memperluas budi pekerti, serta meningkatkan pengetahuan dan kemampuan berbahasa.

6. Menghargai dan membanggakan sastra Indonesia sebagai khasanah budaya dan intelektual manusia Indonesia.
Untuk mencapai tujuan tersebut, pembelajaran bahasa Indonesia terdiri dari empat aspek keterampilan yaitu menyimak, berbicara, membaca, dan menulis. Keempat aspek tersebut menjadi fokus dari tujuan pembelajaran bahasa Indonesia. Keterampilan menyimak dan berbicara dikatagorikan dalam keterampilan lisan, sedangkan keterampilan menulis dan membaca dikatagorikan dalam ketrerampilan berbahasa tulis. Adapun keempat asspek keterampilan ini pada pelaksanaannya disajikan secara terpadu. Dari empat keterampilan berbahasa tersebut, membaca merupakan salah satu keterampilan yang perlu ditingkatkan secara berkelanjutan. Rahim (2007:2) mengatakan bahwa, "Membaca pada hakikatnya adalah suatu yang rumit yang melibatkan banyak hal, tidak sekedar melafalkan tulisan, tetapi juga melibatkan aktivitas visual, berpikir, psikolinguistik, dan metakognitif". Sedangkan menurut Tarigan (2013:7) mengatakan bahwa, "Membaca adalah suatu proses yang dilakukan serta dipergunakan oleh pembaca untuk memperoleh pesan yang hendaknya disampaikan oleh penulis melalui media katakata atau bahasa tulis". Dari kedua pendapat tersebut dapat disimpulkan, bahwa membaca merupakan suatu proses yang rumit yang dilakukan oleh pembaaca, tidal sekedar melafalkan tulisan, tetapi juga melibatkan aktivitas visual, berpikir, psikolinguistik, dan metakognitif untuk memperoleh pesan yang hendak disampaikan penulis melalui bahasa tulis.

Proses pembelajaran membaca hendaknya melihat secara utuh dan menyeluruh jenis membaca yang dilakukan dan strategi yang tepat untuk digunakan. Hal ini dilakukan karena isi setiap materi pelajaran dapat digali dan dimengerti dengan baik melalui kegiatan membaca yang baik dan benar. Kegiatan ini berguna untuk menyerap informasi yang disampaikan penulis dalam setiap bacaan dengana tepat. Kemampuan guru menciptakan dan mengkondisikan kesiapan belajar sangat menentukan berhasil tidaknya suatu proses pembelajaran dilaksanakan.

Salah satu strategi pembelajaran yang digunakan guru agar dapat memiliki kesesuain dengan karakteristik memahami bacaan adalah strategi yang memiliki langkah-langkah 
dalam membaca. Sehingga pembelajaran akan mengacu kepada pembelajaran yang berpusat kepada siswa, dimana siswa akan membaca dan memahami bacaan itu sendiri. Strategi pembelajaran yang efektif dan cocok yang dapat berpengaruh pada hasil belajar siswa yaitu dengan memilih strategi PQ4R (Preview, Question, Read, Reflect, Recite, dan Review). Karena, menurut beberapa teori strategi PQ4R sangat cocok untuk meningkatkan ketrampilan membaca, yaitu setiap tahapan pembelajaran mampu memotivasi siswa untuk mencari, menginggat, dan memahami informasi yang di dapat dari hasil membaca cerita atau bahan bacaan lainnya. Adapun beberapa kelebihan yang mendasari penggunaan strategi PQ4R, yaitu. 1. Dapat membantu siswa yang daya ingatnya lemah untuk menghafal konsepkonsep pelajaran, 2. Mudah diterapkan disemua jenjang pendidikan, 3. Mampu membantu siswa dalam meningkatkan keterampilan proses bertanya dan mengomunikasikan pengetahuannya, dan 4 . Dapat menjangkau materi pelajaran dalam cakupan luas.

Menurut Hamzah dan Nurdin (2014:113), "Strategi PQ4R merupakan strategi yang digunakan untuk membantu siswa mengingat apa yang mereka baca dengan tujuan untuk mempelajarai sampai tuntas bab demi bab suatu buku pelajaran". Sedangkan Trianto (2010:150), berpendapat bahwa, "Strategi PQ4R merupakan strategi yang digunakan untuk membuat siswa mengingat apa yang mereka baca dan dapat membantu proses belajar mengajar di kelas yang dilaksanakan dengan kegiatan membaca buku."

Dari kedua pendapat di atas dapat disimpulkan bahwa, strategi PQ4R merupakan strategi pembelajaran yang digunakan siswa untuk mengingat apa yang mereka baca dan dapat membantu proses belajar di kelas yang dilaksanakan dengan kegiatan membaca buku untuk mempelajari sampai tuntas pada suatu buku pelajaran. Oleh karena itu Strategi PQ4R akan lebih efektif digunakan dalam keterampilan membaca. Adapun langkahlangkah strategi PQ4R adalah sebagai berikut.

1. Preview. Pada kegiatan awal ini dimaksudkan agar peserta didik memfokuskan bahan bacaan untuk menemukan ide-ide pokok melalui kegiatan membaca selintas dengan cepat.

2. Question. Pada kegiatan ini peserta didik diminta merumuskan atau mengajukan pertanyaan-pertanyaan kepada diri sendiri untuk setiap pasal yang ada pada bahan bacaan peserta didik yang meliputi $5 \mathrm{~W}+$ $1 \mathrm{H}$ (what, who, where, when, why, and how).

3. Read. Pada kegiatan berikutnya peserta didik membaca bacaan secara aktif dan detail dari bahan bacaan yang dipelajarinya. Pada tahap ini peserta didik diarahkan untuk mencari jawaban terhadap pertanyaan yang telah dirumuskan.

4. Reflect. Pada kegiatan ini selama membaca, peserta didik tidak cukup mengingat atau menghafal, tetapi yang terpenting adalah peserta didik mampu berdialog atau memahami informasi yang dibacanya.

5. Recite. Pada kegiatan selanjutnya peserta didik diminta untuk merenungkan (mengingat) kembali informasi yang telah dipelajari dengan menyatakan butir-nutir penting dengan nyaring dan dengan menanyakan dan menjawab pertanyanpertanyan dan

6. Review. Pada kegiatan terakhir ini peserta didik diminta untuk membuat rangkuman atau merumuskan catatan singkat (intisari) dari bahan yang telah dibacanya. Peserta didik mampu merumuskan kesumpulan sebagai jawaban dari pertanyaanpertanyaan yang telah diajukan.

Berdasarkan uraian di atas, penelitian ini bertujuan untuk menganalisis pengaruh strategi PQ4R dalam pembelajaran bahasa Indonesia di kelas tinggi sekolah dasar dengan menggunakan metode meta-analysis.

\section{METODE PENELITIAN}

Metode dalam penelitian ini menggunakan metode meta-analisis dengan menelaah dua artikel dengan alasan sebagai berikut.

1. Dari empat puluh artikel yang di download pada google schooler, yang sesuai kreteria meta-analysis hanya dua artikel. 
2. Kebanyakan yang ada, membahas tentang penelitian kualitatif dan peningkatan (PTK),

3. Subyek penelitian yang muncul untuk strategi PQ4R pada materi bahasa Indonesia banyak digunakan pada SMP dan SMA,

4. Tidak ada rata-rata nilai kelas eksperimen, rata-rata nilai kelas kontrol dan nilai rata-rata standar deviasi kelas kontrol, dan

5. Kebanyakan yang ditemui hanya nilai pretest dan postest tidak ada standar deviasi.

Menurut Ruswana Anwar (2005) "Meta-analisis merupakan suatu statistika untuk menggabungkan hasil dua atau lebih penelitian sejenis sehingga diperoleh paduan data secara kuantitatif". Dari pendapat tersebut dapat disimpulkan bahwa meta-analisis merupakan sebuah statistika yang menggabungkan dua atau lebih hasil penelitian sehingga diperoleh data kuantitatif.

Adapun langkah-langkah dalam melakukan meta-analisis secara umum menurut Bloom (2009:15) adalah sebagai berikut.

1. Menentukan dan mempelajari topik penelitian yang dirangkum.

Dalam penelitian ini memilih topik metaanalisis pengaruh strategi $\mathrm{PQ} 4 \mathrm{R}$ dalam pembelajaran bahasa Indonesia di sekolah dasar

2. Mencari dan mengumpulkan sejumlah penelitian yang sesuai dengan topik.

Pencarian hasil penelitian dilakukan dengan menggunakan mesin pengindeks artikel jurnal google scholar. Penyeleksian hasil penelitian dilakukan untuk mempermudah analisis data dengan menggunakan Tabel sebagai berikut.

Tabel 1 : Penelitian Terdahulu

\begin{tabular}{|c|c|c|c|c|c|c|c|}
\hline \multirow[b]{2}{*}{ No } & \multirow[b]{2}{*}{ Judul Penelitian } & \multirow[b]{2}{*}{ Peneliti } & \multirow[b]{2}{*}{ Tahun } & \multicolumn{4}{|c|}{ Hasil } \\
\hline & & & & $\begin{array}{c}\mathbf{T} \\
\text { Eksperimen }\end{array}$ & $\begin{array}{c}x \\
\text { Kontrol }\end{array}$ & $\begin{array}{c}\text { SD } \\
\text { Kontrol }\end{array}$ & Hasil \\
\hline 1 & $\begin{array}{l}\text { Pengaruh Strategi Belajar } P Q 4 R \\
\text { Terhadap Keterampilan Membaca } \\
\text { Pemahaman Siswa Kelas V Sekolah } \\
\text { Dasar (Sinta, Halidjah,\& Kresnadi, } \\
\text { 2019) }\end{array}$ & $\begin{array}{l}\text { Sinta, Siti } \\
\text { Halidjah, Hery } \\
\text { Kresnadi }\end{array}$ & 2019 & 81,31 & 63,18 & 13,57 & $\begin{array}{l}\text { Strategi } P Q 4 R \\
\text { berpengaruh terhadap } \\
\text { keterampilan membaca }\end{array}$ \\
\hline 2 & $\begin{array}{l}\text { Perbedaan Model Pembelajaran } \\
P Q 4 R \text { dan } S Q 3 R \text { Terhadap Hasil } \\
\text { Belajar Siswa Kelas IV di SD } \\
\text { Gugus Diponegoro pada Tema } \\
\text { Indahnya Keragaman di Negeriku } \\
\text { (Putri A.R et all, 2019) }\end{array}$ & $\begin{array}{l}\text { Ayuk } \\
\text { Rismaya Putri, } \\
\text { Bambang } \\
\text { Suteng, } \\
\text { Eunice } \\
\text { Widyanti S }\end{array}$ & 2019 & 75,63 & 66,75 & 10,595 & $\begin{array}{l}\text { Model } P Q 4 R \\
5 \text { berpengaruh pada hasil } \\
\text { belajar Bahasa Indonesia }\end{array}$ \\
\hline
\end{tabular}

3. Melakukan perhitungan effect size pada hasil penelitian yang telah ditentukan. Perhitungan effect size dilakukan dengan menggunakan rumus dan kriteria sebagai berikut.

$$
\Delta=\frac{x \text { eksperimen }-x \text { kontrol }}{S D \text { kontrol }}
$$

Sumber: Glass (1981)

dengan kriteria ukuran efek sebagai berikut:

a. effect size $\leq 0,15$ efek yang dapat diabaikan b. $0,15<$ effect size $\leq 0,40$ efek kecil

c. $0,40<$ effect size $\leq 0,75$ efek sedang

d. $0,75<$ effect size $\leq 1,10$ efek tinggi

e. $1,10<$ effect size $\leq 1,45$ efek yang sangat tinggi

f. $1,45<$ effect size pengaruh yang tinggi

4. Mengidentifikasi ada tidaknya besaran effect size.

Dengan melihat kesesuaian dari hasil perhitungan effect size yaitu memberikan efek kecil, efek sedang, efek tinggi, dan efek yang sangat tinggi atau efek pengaruh tinggi. 
5. Menarik kesimpulan pada hasil penelitian meta-analisis.

Menyimpulkan setiap hasil dari meta analisis yang telah dilakukan dan sesuai dengan besaran effect size yang telah ditentkan.

\section{HASIL DAN PEMBAHASAN}

Berdasarkan hasil penelitian dari kedua penelitian terdahulu, diperoleh besar efek sebagai berikut.

1. Pengaruh Strategi Belajar $P Q 4 R$ terhadap Keterampilan Membaca Pemahaman Siswa Kelas V Sekolah Dasar

Pengaruh strategi PQ4R terhadap keterampilan membaca Bahasa Indonesia kelas IV diketahui memberikan efek size pengaruh yang tinggi. Dibuktikan dengan besarnya efek sejumlah $(1,33)$ yang artinya memberikan efek yang sangat tinggi. Jadi dapat disimpulkan strategi $P Q 4 R$ memiliki pengaruh yang sangat tinggi terhadap keterampilan membaca pemahaman siswa kelas V Sekolah Dasar.

$$
\begin{aligned}
& \Delta=\frac{x \text { eksperimen-xkontrol }}{S D \text { kontrol }} \\
& \Delta=\frac{81,31-63,18}{13,57}=1,33
\end{aligned}
$$

Tabel 2 : Nilai perolehan Skor Artikel 1

\begin{tabular}{cc}
\hline$\Delta$ & Kriteria effect size \\
\hline 1,33 & Efek yang sangat tinggi \\
\hline
\end{tabular}

2. Perbedaan Model Pembelajaran $P Q 4 R$ dan $S Q 3 R$ terhadap Hasil Belajar Siswa Kelas IV di SD Gugus Diponegoro pada Tema Indahnya Keragaman di Negeriku.

Hasil penelitian meta-analisis pengaruh strategi $P Q 4 R$ terhadap hasil belajar memberi pengaruh efek size tinggi. Dibuktikan dengan besarnya efek sejumlah $(0,84)$ yang artinya memberikan efek tinggi. Dengan demikian dapat disimpulkan bahwa, model $P Q 4 R$ memberikan efek yang tinggi terhadap hasil belajar siswa kelas IV di SD Gugus Diponegoro pada tema Indahnya Keragaman di Negeriku.

$$
\Delta=\frac{x \text { eksperimen }-x \text { kontrol }}{S D \text { kontrol }}
$$

$$
\Delta=\frac{75,63-66,75}{10,595}=0,84
$$

Tabel 3 : Nilai Perolehan Skor Artikel 2

\begin{tabular}{cc}
\hline$\Delta$ & Kriteria effect size \\
\hline 0,84 & Efek tinggi \\
\hline
\end{tabular}

Hasil meta-analisis pengaruh strategi PQ4R terhadap keterampilan membaca, ditemukan bahwa strategi PQ4R terhadap hasil belajar siswa sekolah dasar memberikan pengaruh yang positif.

Pada analisis data yang dilakukan oleh Sinta, Siti Halidjah, Hery Kresnadi diperoleh hasil Effect Size sebesar 1,33 yang menunjukkan efek yang sangat tinggi, dapat disimpulkan bahwa strategi pembelajaran PQ4R terhadap keterampilan membaca memiliki efek pengaruh yang sangat tinggi di kelas tinggi sekolah dasar. Hal tersebut sejalan dengan pendapat Tarigan (2015:7), "Membaca adalah suatu proses yang dilakukan serta dipergunakan oleh pembaca untuk memperoleh pesan yang hendak disampaikan oleh penulis melalui media kata-kata atau bahasa tulis". Dengan demikian membaca merupakan proses yang dilakukan oleh pembaca untuk memeperoleh pesan yang hendak disampaikan oleh penulis. Sedangkan menurut Abidin, Yunus (2012:60), "Membaca pemahaman diartikan sebagai proses sungguhsungguh yang dilakukan pembaca untuk memperoleh informasi, pesan, dan makna yang terkandung dalam sebuah bacaan". Dengan demikian membaca pemahaman merupakan proses yang dilakukan oleh pembaca dengan sungguh-sunguh untuk memperoleh informasi pada sebuah bacaan.

Pada analisis data yang dilakukan oleh Ayuk Rismaya Putri, Bambang Suteng, Eunice Widyanti diperoleh Effect Size 0,84 yang menunjukkan efek tinggi, dapat disimpulkan bahwa model PQ4R berpengaruh terhadap hasil belajar siswa pada kelas tinggi sekolah dasar. Hal tersebut sejalan dengan pendapat Savitry, Arcana, dan Agung (2013:3), "PQ4R merupakan model pembelajaran yang dapat membantu siswa untuk mengingat apa yang mereka baca dan melatih siswa untuk bertanggung jawab atas materi yang mereka 
pelajari, dan memberikan kesempatan kepada siswa untuk mengembangkan potensi diri dan belajar lebih aktif." Dengan demikian dapat diketahui bahwa, model $P Q 4 R$ merupakan model pembelajaran untuk siswa agar dapat mengingat apa yang mereka baca sehingga siswa dapat mengembangkan potensi diri dan belajar lebih aktif. Sedangkan model pembelajaran $S Q 3 R$ menurut Huda (2015:245), menjelaskan bahwa "Model $S Q 3 R$ merupakan model yang membantu peserta didik dalam pemahaman materi atau teks yang dibaca". Dengan demikian model $S Q 3 R$ merupakan model yang diajarkan melalui pemahaman materi atau teks yang dibaca. Widoyoko (2014:25), "Hasil belajar merupakan hasil dari suatu interaksi tindak belajar mengajar dan biasanya di tunjukkan dengan nilai tes yang diberikam guru". Dengan demikian hasil belajar dapat diartikan sebagai suatu interaksi dari hasil belajar dan biasanya ditunjukkan berupa nilai. Sedangkan Hardini (2017:193), "Berpendapat bahwa hasil belajar siswa mencakup ranah kognitif, afektif, dan psikomotor". Dengan demikian dapat disimpulkan hasil belajar merupakan kemampuan siswa yang mencakup ranah kognitif, afektif, dan psikomotor. Dari kedua pendapat tersebut dapat disimpulkan bahwa, hasil belajar merupakan suatu interaksi tindakan belajar siswa yang mencakup tiga ranah yaitu kognitif, afektif, dan psikomotor.

\section{SIMPULAN DAN SARAN}

Berdasarkan uraian dari pembahaasan arikel tersebut, maka kesimpulan dalam penelitian ini sebagai berikut.

1. Strategi atau model $P Q 4 R$ pada materi pelajaran bahasa Indonesia berpengaruh terhadap keterampilan membaca maupun hasil belajar siswa kelas tinggi sekolah dasar.

2. Strategi $P Q 4 R$ Pada artikel yang pertama hasil hitung besarnya efek sebesar $(1,33)$ yang memiliki arti efek yang sangat tinggi dan pada artikel kedua besaranya efek sebesar( 0.84) dapat artikan effect size efek tinggi. sehingga Strategi $P Q 4 R$ dalam pelajaran bahasa Indonesia sangat berpengaruh terhadap hasil belajar dan dapat melatih kemampuan mengingat bagi siswa pada saat membaca pada materi pelajaran di kelas tinggi sekolah dasar.

\section{DAFTAR PUSTAKA}

Abidin. Y. 2012. Pembelajaran Membaca Berbasis Pendidikan Karakter. Bandung: Refika Aditama.

Ayuk Rismaya Putri, Bambang Suteng, dan Eunice Widyanti S. (2019). Perbedaan Model Pembelajaran PQ4R dan SQ3R terhadap Hasil Belajar Siswa Kelas IV di SD Gugus Diponegoro pada Tema Indahnya Keragaman Di Negeriku. EJurnal Mitra Pendidikan, 3(3), 388-401. Retrieved jurnalmitrapendidikan.com/index.php/eimp/article/view/515

B.Uno, Hamzah. 2014. Belajar Dengan Pendekatan Paikem. Jakarta: PT Bumi Aksara

Bloom, J. De, Kompier, M., Geurts, S., Weerth, C. De, Taris, T., \& Sonnenteng, S. 2009. Do We Recover From Vacation, Meta-analysis of Vaction Effects On Health and Well-being. Journal of Occupational.

Glass, G.v. McGaw B., \& Smith, M.L. 1981. Meta-analisis in Social Research. London: Sage Publications.

Hardani. 2017. Penerapan Pendekatan Pembelajaran Inkuiri Untuk Meningkatkan Keaktifan Dan Hasil Belajar Siswa. Sholaria, Vol 7. No. 1

Huda. 2015. Model-Model Pengajaran Dan Pembelajaran. Yogyakarta: Pustaka Pelajar.

Rahim, Farida. 2007. Pengajaran Membaca di Sekolah Dasar. Jakarta: Bumi Aksara.

Samsiyah, Nur. 2016. Pembelajaran Bahasa Indonesia di SD Kelas Tinggi. Magetan: CV. Merdeka Grafika.

Savitry, Arcana, dan Agung. 2013. Pengaruh Strategi pembelajaran PQ4R Berbantu Media Gambar Tehadap Hasil Belajar IPS Siwa Kelas IV di SD Gugus IV Kecamatan Sawan. Mimbar PGSD UNDHISKA, Vol 1 , No 1.

Sinta, S., Halidjah, S., \& Kresnadi, H. (2019). Pengaruh Strategi Belajar PQ4R terhadap Keterampilan Membaca Pemahaman Siswa Kelas V Sekolah Dasar. Jurnal Pendidikan dan Pembelajaran 
Khatulistiwa Vol 8, No 5. Retrieved from http://jurnal.untan.ac.id/index.php/ipdpb/a $\underline{\text { rticle/view/33113 }}$

Sugono, Dendy. 2009. Mahir Berbahasa Indonesia Dengan Benar. Jakarta: PT. Gramedia Pustaka Utama.

Tarigan. G. H. 2013. Membaca Sebagai Suatu Keterampilan Berbahasa. Bandung: Angkasa Bandung.

Trianto. 2010. Mendesain Model Pembelajaran Inovatif-Progresif. Jakarta: Kencana Prenada Media Group

Windoyoko. 2014. Penilaian Hasil Belajar di Sekolah. Yogyakarta: Pustaka Belajar 